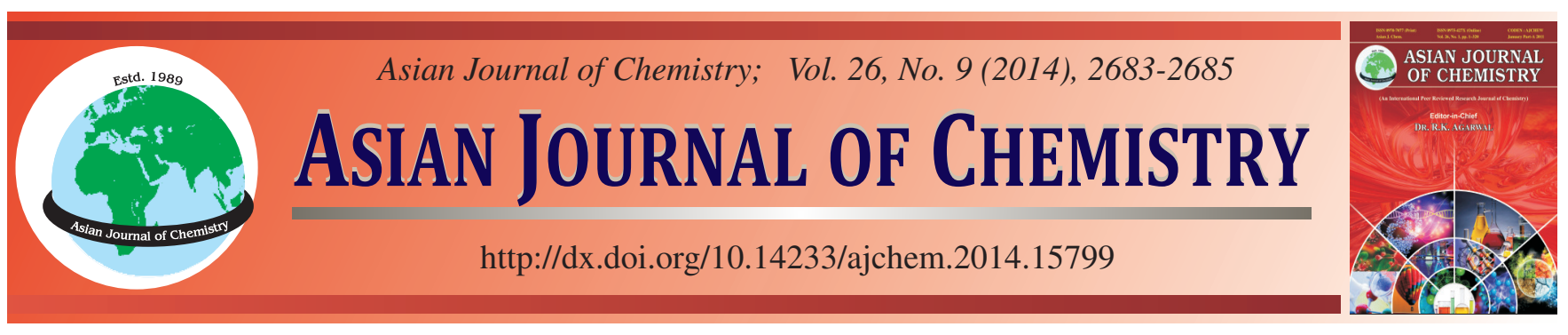

\title{
Direct Hydroxylation of Benzene to Phenol Over Pyridine-Modified Vanadium-Substituted Heteropoly Acid Under Microwave Condition
}

\author{
T. LIU ${ }^{1, *}$ and J.H. Hou ${ }^{2}$
}

${ }^{1}$ School of Chemistry \& Chemical Engineering, Xuzhou Institute of Technology, Xuzhou 221111, Jiangsu Province, P.R. China ${ }^{2}$ School of Food (Biology) Engineering, Xuzhou Institute of Technology, Xuzhou 221111, Jiangsu Province, P.R. China

*Corresponding author: E-mail: liutongcumt@126.com

\begin{abstract}
Direct oxidation of benzene to phenol over $\mathrm{Py}_{3} \mathrm{PMo}_{11} \mathrm{~V}$ and hydrogen peroxide as the oxidant under microwave irradiation. Pyridine(Py)modified vanadium substituted heteropoly acid $\left(\mathrm{Py}_{3} \mathrm{PMo}_{11} \mathrm{~V}\right)$ with Keggin structure was prepared and characterized by FT-IR. The influence of different reaction conditions, such as the reaction time, the amount of catalyst used, the amount of hydrogen peroxide used and the reaction temperature on the yield of phenol was studied to obtain the optimal reaction conditions for phenol formation. Coupled conventionally heated method gives phenol yield of $7.8 \%$, higher phenol yield of $24.7 \%$ and selectivity of $100 \%$ are obtained when irradiated with microwave energy.
\end{abstract}

Keywords: Oxidation of benzene, Phenol, Hydrogen peroxide, Microwave irradiation, Pyridine.

\section{INTRODUCTION}

Phenol is one of the most important intermediates of chemical industry ${ }^{1}$. It is mainly produced by cumene process. However, this process suffers mainly from low atom utilization, low phenol yield, high energy consumption and the production of equal amount of acetone as the by product ${ }^{2}$. Therefore, the study of the direct hydroxylation of benzene to phenol has attracted increasing interests for last decades ${ }^{3-5}$.

In recent years, there has been an increasing interest in Keggin-type heteropoly acids as catalysts for the hydroxylation of benzene to phenol, in which the substituted vanadium is known as the most active metal species ${ }^{6,7}$. Moreover, because the strong acidity and redox property of Keggin-type heteropoly acids can be controlled by replacing the protons with metal cations and/or by changing the heteroatom or the framework transition-metal atoms, therefore, they have been studied for various reactions $^{8-12}$.

Microwave irradiation (MWI) as an energy source for many chemical reactions has been studied in recent years ${ }^{13}$. These studies show that it is well documented to significantly accelerate a wide range of chemical reactions, especially in a polar system, under mild conditions ${ }^{14}$.

In the present work, $\mathrm{Py}_{3} \mathrm{PMo}_{11} \mathrm{~V}$ was used as catalyst for the liquid-phase hydroxylation of benzene with $30 \% \mathrm{H}_{2} \mathrm{O}_{2}$ as an oxidant and observe the influence of microwave irradiation on catalytic reaction. The microwave provides more parameters for convenient adjustment of reaction conditions. An obvious promotion effect of the catalyst on the phenol yield and selectivity was observed for this reaction.

\section{EXPERIMENTAL}

Catalyst preparation: All the reagents, including benzene, $\mathrm{MoO}_{3}$, pyridine, $\mathrm{V}_{2} \mathrm{O}_{5}, \mathrm{H}_{3} \mathrm{PO}_{4}(85 \%), \mathrm{H}_{2} \mathrm{O}_{2}$ (30\% by weight) and acetonitrile, were commercially purchased and used without further purification.

The detailed procedure for the catalyst $\mathrm{Py}_{3} \mathrm{PMo}_{11} \mathrm{~V}$ preparation was as follows ${ }^{11}: 14.4 \mathrm{~g} \mathrm{MoO}_{3}$ and $0.92 \mathrm{~g} \mathrm{~V}_{2} \mathrm{O}_{5}$ were suspended in $250 \mathrm{~mL}$ deionized water in a $500 \mathrm{~mL}$ threenecked flask equipped with a condenser under magnetic stirring in an oil bath at the reflux temperature. $1.15 \mathrm{~g}$ aqueous $85 \% \mathrm{H}_{3} \mathrm{PO}_{4}$ was added drop-wise to the boiling and stirred suspension of the reaction mixture, a clear orange-red solution was obtained. The solution was cooled to the room temperature and further dried via evaporation to get a solid product, into which a suitable amount of deionized water was added to obtain a solution and then the solution was left at the room temperature overnight to re-crystallize for purification. The resulting fine orange-red powders was $\mathrm{H}_{4} \mathrm{PMo}_{11} \mathrm{VO}_{40}$. The catalyst $\mathrm{Py}_{3} \mathrm{PMo}_{11} \mathrm{~V}$ was prepared by the pyridine $/ \mathrm{H}_{4} \mathrm{PMo}_{11} \mathrm{VO}_{40}$ molar ratio of $3: 1$. Then the solution containing precipitates was evaporated to dryness at $70{ }^{\circ} \mathrm{C}$ and the solid product obtained was further dried at the same temperature overnight in vacuum oven. 
General procedure: The liquid-phase hydroxylation of benzene was carried out: $4 \mathrm{~mL}$ of benzene, $15 \mathrm{~mL}$ acetonitrile, described amounts of $\mathrm{Py}_{3} \mathrm{PMo}_{11} \mathrm{~V}$ and $\mathrm{H}_{2} \mathrm{O}_{2}(30 \%)$ along with a magnetical stirrer were added into a $50 \mathrm{~mL}$ microwave reactor. The reactor was heated to an indicated temperature and kept at that temperature for 5-35 $\mathrm{min}$. Then the reactor was immediately cooled to room temperature by purging compressed air. The reaction mixture was analyzed by gas chromatography.

The IR spectra of $\mathrm{Py}_{3} \mathrm{PMo}_{11} \mathrm{~V}$ was measured using a $\mathrm{KBr}$ disk mounted in an infrared spectrophotometer (ALPHA). Sample was mixed and grounded with $\mathrm{KBr}$ for IR measurement.

The terms of reaction performance were defined as follows:

$$
\text { Yield of phenol }=\frac{\text { Mole of phenol produced }}{\text { Initial mole of benzene }}
$$

Selectivity of phenol $=\frac{\text { Mole of phenol produced }}{\text { Mole of benzene reacted }}$

\section{RESULTS AND DISCUSSION}

Catalyst characterization: The IR spectra of $\mathrm{Py}_{3} \mathrm{PMo}_{11} \mathrm{~V}$ is given in Fig. 1. The four IR vibration peaks assigned to a Keggin-type heteropoly acid can be seen from Fig. 1 and the locations of featured peaks (PsO, $1060 \mathrm{~cm}^{-1}$; MosOsMo, 966 $\mathrm{cm}^{-1}$; ModO, 863 and $779 \mathrm{~cm}^{-1}$ ) are in well agreement with those in the previous report ${ }^{11}$. After the reaction of pyridine with $\mathrm{H}_{4} \mathrm{PMo}_{11} \mathrm{VO}_{40}$, the corresponding two peaks (1435 and $1381 \mathrm{~cm}^{-1}$ ) of pyridine shifts to 1530 and $1484 \mathrm{~cm}^{-1}$, respectively.

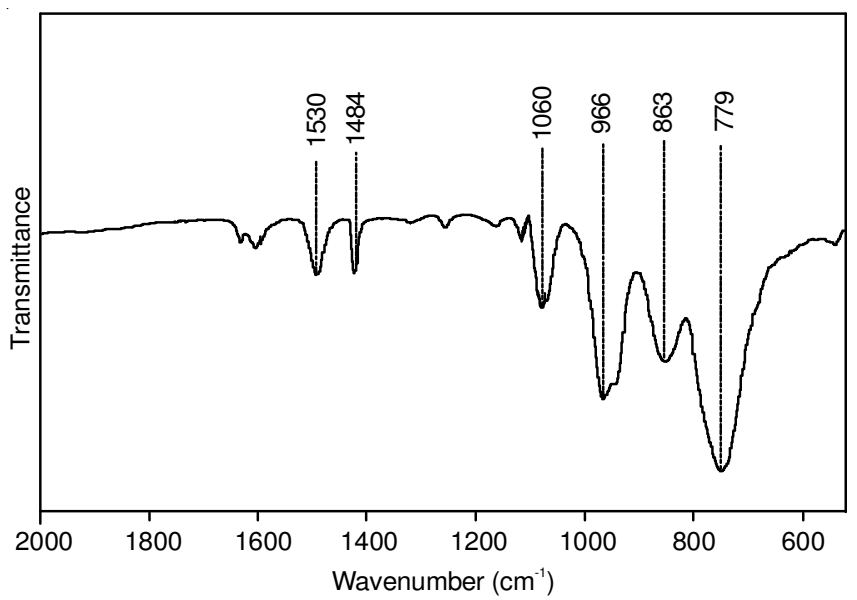

Fig. 1. FTIR spectra of $\mathrm{Py}_{3} \mathrm{PMo}_{11} \mathrm{~V}$ catalyst

Effect of the reaction temperature on the yield of phenol under microwave irradiation: The effect of the reaction temperature on the yield of phenol over $\mathrm{Py}_{3} \mathrm{PMo}_{11} \mathrm{~V}$ under microwave irradiation is shown in Fig. 2. It was indicated that the reaction temperature increased from 40 to $50{ }^{\circ} \mathrm{C}$. The yield of phenol increased slowly from 11.4 to $13.5 \%$, showing a very slow reaction. When the reaction temperature was raised to $70{ }^{\circ} \mathrm{C}$, a sharp increase to $24.7 \%$ yield of phenol was obtained. However, when the reaction temperature was further up to $80^{\circ} \mathrm{C}$, caused the remarkable decrease of phenol yield

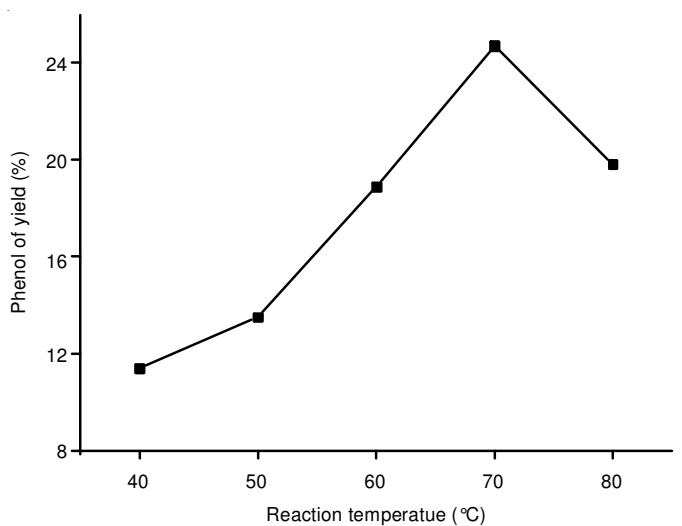

Fig. 2. Effect of reaction temperature on the yield of phenol. Reaction conditions: $0.15 \mathrm{~g}$ catalyst, $1 \mathrm{~mL}$ benzene, $1.8 \mathrm{~mL} \mathrm{H}_{2} \mathrm{O}_{2}, 15 \mathrm{~mL}$ acetonitrile, time $20 \mathrm{~min}$

to $19.7 \%$. This is mostly caused by decomposition of $\mathrm{H}_{2} \mathrm{O}_{2}$ proceeded faster at high temperature, leading to the excessive oxidation of the phenol and the lower value of the phenol yield. The above data indicate that the reaction temperature was increased to $70^{\circ} \mathrm{C}$ promotes the production of phenol and selfdecomposition of hydrogen peroxide. We have confirmed this trend by repeately carrying out this test. So, $70^{\circ} \mathrm{C}$ is considered as a suitable hydroxylation reaction temperature.

Effect of the amount of $\mathrm{H}_{2} \mathrm{O}_{2}$ on the yield of phenol under microwave irradiation: The influence of $\mathrm{H}_{2} \mathrm{O}_{2}$ as the oxident reagent on the yield of phenol was investigated using $\mathrm{Py}_{3} \mathrm{PMo}_{11} \mathrm{~V}$ as the catalyst and the effect of the amount of $\mathrm{H}_{2} \mathrm{O}_{2}$ on the yield of phenol is illustrated in Fig. 3. No phenol was obtained without the use of $\mathrm{H}_{2} \mathrm{O}_{2}$. The phenol yield was found to increase with the increase of the amount of $\mathrm{H}_{2} \mathrm{O}_{2}$ and reached a maximum value of $24.7 \%$ at $1.8 \mathrm{~mL}$. Further increase of the amount of $\mathrm{H}_{2} \mathrm{O}_{2}$ had a reverse influence on the phenol yield, which result from the further oxidation of the phenol formed, the benzoquinone was observed. Therefore, $1.8 \mathrm{~mL}$ is considered as a suitable amount in this reaction.

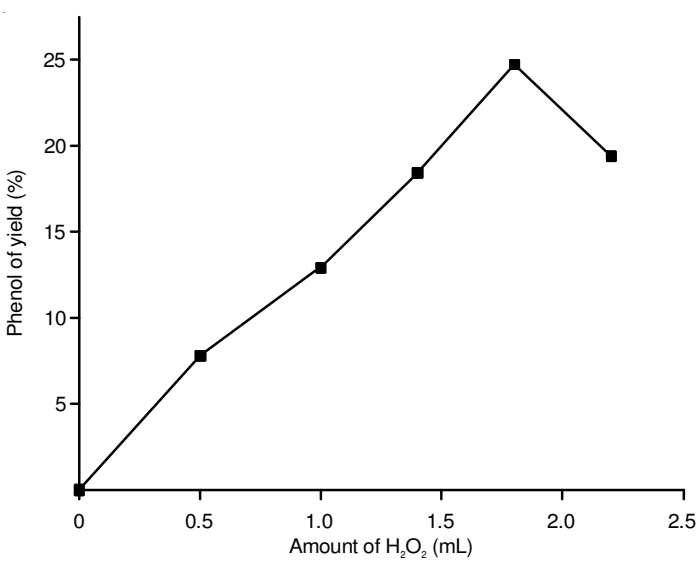

Fig. 3. Effect of $\mathrm{H}_{2} \mathrm{O}_{2}$ amount on the yield of phenol. Reaction conditions: $0.15 \mathrm{~g}$ catalyst, $1 \mathrm{~mL}$ benzene, $15 \mathrm{~mL}$ acetonitrile, $70^{\circ} \mathrm{C}$, time 20 $\min$

Effect of the amount of catalyst on the yield of phenol under microwave irradiation: The effect of the amount of the $\mathrm{Py}_{3} \mathrm{PMo}_{11} \mathrm{~V}$ on the yield of phenol was investigated at $70{ }^{\circ} \mathrm{C}$ 
and the results is shown in Fig. 4. No phenol was detected without the use of the $\mathrm{Py}_{3} \mathrm{PMo}_{11} \mathrm{~V}$, which indicated that $\mathrm{Py}_{3} \mathrm{PMo}_{11} \mathrm{~V}$ is essential for performing the reducer. The yield of phenol was increased from 0 to $24.7 \%$ with the increase amount of the $\mathrm{Py}_{3} \mathrm{PMo}_{11} \mathrm{~V}$. When amount of the $\mathrm{Py}_{3} \mathrm{PMo}_{11} \mathrm{~V}$ is $0.15 \mathrm{~g}$, the yield of phenol reached $24.7 \%$ with a selectivity of $100 \%$. But further increase in the amount of the $\mathrm{Py}_{3} \mathrm{PMo}_{11} \mathrm{~V}$ inversely caused a decrease in the yield of phenol. Therefore, $0.15 \mathrm{~g} \mathrm{Py}_{3} \mathrm{PMo}_{11} \mathrm{~V}$ is considered as a suitable amount in this reaction.

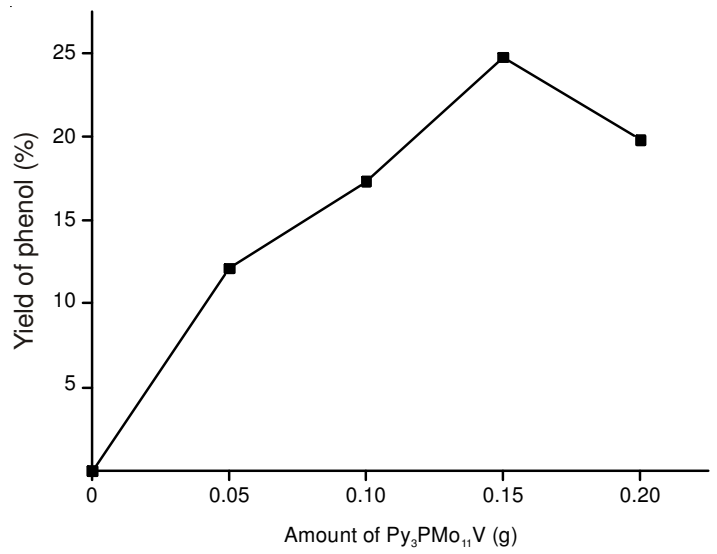

Fig. 4. Effect of catalyst amount on the yield of phenol. Reaction conditions: $1 \mathrm{~mL}$ benzene, $1.8 \mathrm{~mL} \mathrm{H}_{2} \mathrm{O}_{2}, 15 \mathrm{~mL}$ acetonitrile, $70{ }^{\circ} \mathrm{C}$, time $20 \mathrm{~min}$

Effect of the reaction time on the yield of phenol under microwave irradiation: The influence of reaction time on the yield of phenol over $\mathrm{Py}_{3} \mathrm{PMo}_{11} \mathrm{~V}$ is shown in Fig. 5. It can be observed that the yield of phenol was a sharply increased to $24.7 \%$ with the increased of reaction time up to $20 \mathrm{~min}$. However, the yield decreased with the further increase of reaction time, which is due to the further oxidation of phenol. So $20 \mathrm{~min}$ is chosen as a suitable reaction time in this work.

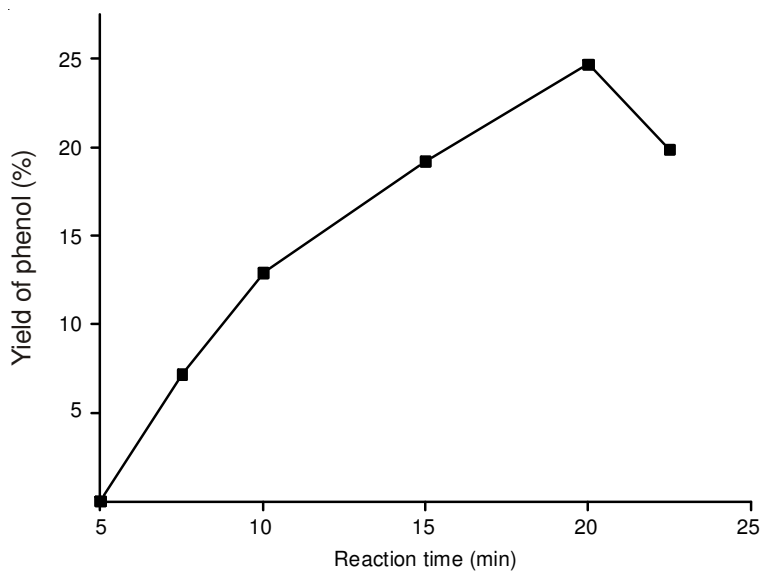

Fig. 5. Effect of reaction time on the yield of phenol. Reaction conditions: $0.15 \mathrm{~g}$ catalyst, $1 \mathrm{~mL}$ benzene, $1.8 \mathrm{~mL} \mathrm{H}_{2} \mathrm{O}_{2}, 15 \mathrm{~mL}$ acetonitrile, $70{ }^{\circ} \mathrm{C}$

\section{Conclusion}

Coupled conventionally heated method gives phenol yield of $7.8 \%, \mathrm{Py}_{3} \mathrm{PMo}_{11} \mathrm{~V}$ exhibits higher activity for the hydroxylation of benzene with $100 \%$ selectivity of phenol and $24.7 \%$ phenol yield under microwave irradiation at the optimum reaction conditions: $1.0 \mathrm{~mL}$ benzene, $0.15 \mathrm{~g}$ catalyst, $1.8 \mathrm{~mL}$ $30 \%$ aqueous solution of $\mathrm{H}_{2} \mathrm{O}_{2}, 15 \mathrm{~mL}$ acetonitrile, $70{ }^{\circ} \mathrm{C}$ reaction temperature and 20 min reaction time.

Analysis the results, concluded that the substituted vanadium atom with high dielectric loss factor in heteropoly acid, can couple easily with microwave energy and gets heated, is essentially active site with higher performance for the hydroxylation of benzene to phenol under microwave irradiation.

\section{REFERENCES}

1. T. Sakamoto, T. Takagaki, A. Sakakura, Y. Obora, S. Sakaguchi and Y. Ishii, J. Mol. Catal. A, 288, 19 (2008).

2. Y.-Y. Gu, X.-H. Zhao, G.-R. Zhang, H.-M. Ding and Y.-K. Shan, Appl. Catal. A., 328, 150 (2007).

3. M. Tani, T. Sakamoto, S. Mita, S. Sakaguchi and Y. Ishii, Angew. Chem. Int. Ed., 44, 2586 (2005).

4. E. Battistel, R. Tassinari, M. Fornaroli and L. Bonoldi, J. Mol. Catal. A, 202, 107 (2003).

5. C. Gabriel, S. Gabriel, E.H. Grant, E.H. Grant, B.S.J. Halstead and D.M.P. Mingos, Chem. Soc. Rev., 27, 213 (1998).

6. K. Takahashi, T. Okuhara and M. Misono, Chem. Lett., 841 (1985).

7. M. Misono, T. Okuhara, T. Ichiki and Y. Kanda, J. Am. Chem. Soc., 109, 5535 (1987)

8. B. Xu, Y. Wei, C.L. Barnes and Z. Peng, Angew. Chem. Int. Ed., 40, 2290 (2001).

9. Y.Y. Liu, K. Murata and M. Inaba, Catal. Commun., 6, 679 (2005)

10. B.B. Bardin and R.J. Davis, Appl. Catal. A, 185, 283 (1999).

11. H.Q. Ge, Y. Leng, F.M. Zang, C.J. Zhou and J. Wang, Catal. Lett., 124, 250 (2008).

12. F.M. Zhang, J. Wang, C.S. Yuan and X.Q. Ren, Catal. Lett., 102, 171 (2005).

13. G. Bond, R.B. Moyes and D.A. Whan, Catal. Today, 17, 427 (1993).

14. P. Lidström, J. Tierney, B. Wathey and J. Westman, Tetrahedron, 57, 9225 (2001). 